\title{
Effect of Drying on the Reproducibility of DIAGNOdent to Detect Caries-Like Lesions
}

\author{
Camila PINELLI ${ }^{1}$ \\ Leonor de Castro Monteiro LOFFREDO ${ }^{1}$ \\ Mônica Campos SERRA ${ }^{2}$
}

\begin{abstract}
${ }^{1}$ Department of Community Dentistry, Araraquara Dental School, São Paulo State University, Araraquara, SP, Brazil ${ }^{2}$ Department of Restorative Dentistry, Ribeirão Preto Dental School, University of São Paulo, Ribeirão Preto, SP, Brazil
\end{abstract}

\begin{abstract}
The aim of this study was to verify the drying effect on the reproducibility of DIAGNOdent (Dd) devices to detect caries-like lesions. Three areas were created in each of the 34 bovine incisors: sound (S), demineralized (DE) and remineralized (RE). One examiner measured each area with two Dd devices (denominated $\mathrm{X}$ and $\mathrm{Y}$ ), twice under humid, and twice under dry condition. Intra-rater agreement according each device and inter-device agreement were estimated by kappa statistics $(\kappa)$. Intra-rater agreement for device $Y$ was substantial under humid $\left(\kappa_{\mathrm{DE}}=0.68\right.$ and $\left.\kappa_{\mathrm{RE}+\mathrm{S}}=0.68\right)$ and dry condition $\left(\kappa_{\mathrm{DE}}=0.64\right.$ and $\left.\kappa_{\mathrm{RE}+\mathrm{S}}=0.67\right)$. For device $\mathrm{X}$, it was substantial under humid condition ( $\kappa_{\mathrm{DE}}=0.57$ and $\left.\kappa_{\mathrm{RE}+\mathrm{S}}=0.49\right)$, and it was almost perfect after air drying $\left(\kappa_{\mathrm{DE}}=1.0\right.$ and $\left.\kappa_{\mathrm{RE}+\mathrm{S}}=1.0\right)$. Inter-device agreement was slight $(\kappa=0.17)$ under humid condition, and it was substantial under dry condition $(\kappa=0.62)$. As reproducibility increased under dry condition, drying is advised to detect caries-like lesions on free smooth surfaces when different devices are used.
\end{abstract}

Key Words: dental caries, fluorescence, lasers, tooth demineralization, reproducibility of results.

\section{INTRODUCTION}

Diagnosis of caries lesions activity is of importance for a correct treatment plan for the caries disease (1). DIAGNOdent (Dd) (KaVo, Biberach, Germany) is an instrument developed as an aid to early detection of caries lesions, and as a tool to monitor lesion progression over time, as well as to evaluate the outcome of preventive treatment (2).

Regarding dentin caries lesions, evidence has suggested that metabolites rather than mineral content are responsible for fluorescence, as carious lesions fluoresce more strongly than healthy tissues $(3,4)$. It has been shown that Dd values increase as the rates of bacterial detection increase (4). Dd readings have been shown to likely depend on the volume rather than depth of caries (3). In relation to enamel caries lesions, there is some contradiction. Some studies suggested laser fluorescence could be used as a valuable tool and to monitor caries progression $(2,5)$. Other researchers have stated that $\mathrm{Dd}$ was not able to quantify small mineral changes (6), nor remineralization (7).
Also, there is some doubt if different Dd devices would produce consistent results (8-11). Only occlusal surfaces were tested and studies indicate that when two devices were applied to detect caries lesions there were systematic differences in laser readings (11). On the other hand, it was found that a new device could replace an old one provided the same tip would be used (10). It was also indicated that a Dd could be totally replaced by a new one (8). Other research (9) included four devices in the comparison. It was verified that one Dd did not show laser values directly comparable with the other three Dd, while Künisch et al. (9) verified no difference among the four devices tested.

The role of drying before the inspection of the surfaces with Dd is also unclear. Some variability in relation to the use or in the need of air-drying was observed $(1,6,8)$. In occlusal surfaces, Shi et al. (12) reported a systematic difference between data from the same registration under wet and dry conditions.

Regarding free smooth surfaces Pinelli et al. (13) verified the reproducibility and validity of Dd to detect caries lesion activity in vivo. However, no previous study

Correspondence: Profa. Dra. Camila Pinelli, Departamento de Odontologia Social, Faculdade de Odontologia de Araraquara, UNESP, Rua Humaitá, 1680, 331, Centro, 14801-903 Araraquara, SP, Brasil. Tel: +55-16-3301-6346. Fax: +55-16-3301-6343. e-mail: cpinelli@foar.unesp.br 
has been done to verify the reliability of caries diagnosis with different Dd devices, nor tested them under humid and dry condition. Such investigation is relevant because a reliable laser measurement is an essential prerequisite if different devices are used to detect and monitor caries lesions in the same patients (9).

The aim of the present study was to investigate the effect of drying on the reproducibility of Dd to detect caries-like lesions.

\section{MATERIAL AND METHODS}

\section{Tooth Preparation}

Thirty-four bovine teeth (upper incisors) were hand scaled, cleaned with a toothbrush, rinsed thoroughly under tap water, and stored in buffered thymol-saturated saline solution under refrigeration. The teeth were covered with No. 7 wax, with the exception of the 3 circle-delimited windows, each of $5 \mathrm{~mm}$ in diameter, on the buccal surface. Randomization of the 3 windows was made in order to produce sound (S), demineralized (DE), and remineralized (RE) areas. As the $\mathrm{S}$ windows would not be exposed to any cycling procedure they were covered with wax, until the teeth were measured with Dd.

\section{Artificial Caries Lesions Development}

Two windows on each tooth (DE and RE) were exposed to $\mathrm{pH}$ cycles (14). Caries-like lesions were induced by a dynamic model of demineralization and remineralization simulating in vivo conditions of high caries risk (14). Each cycle consisted of immersing the teeth into the demineralizing solution for $6 \mathrm{~h}$, and changing them to the remineralizing solution for $17 \mathrm{~h}$, as described by Serra and Cury (15). After 11 days of demineralization and remineralization, the DE area was covered with wax to represent the demineralized lesions.

\section{Remineralization Procedure}

The window that would represent RE lesions on each tooth was left opened for 28 days in order to get immersed in the remineralization solution (the same solution of the dynamic model) (14).

Thereafter, all the wax was removed and the teeth were cleaned with toothbrush and water. Finally, 102 areas were obtained, in which 34 were S, 34 were DE and 34 were RE. The teeth were stored at $100 \%$ relative humidity with distilled water, under refrigeration, for 2 days, before the laser measurements were conducted.

\section{Laser Fluorescence Measurements}

Two different Dd devices from the same manufacturer $(\mathrm{KaVo})$ were used. One was denominated X (Ser.-Nr.: D290723) and the other Y (Ser.-Nr.: 1100702) in order to identify them. They were previously calibrated following the manufacturer's instruction. The flat tip, designated for smooth surfaces was selected. Prior to the examinations, each device was calibrated against its porcelain standard (Device $\mathrm{X}$ : porcelain standard $=60$; device $\mathrm{Y}$ : porcelain standard $=81$ ).

Readings were performed under humid and under dry conditions. Initially, teeth were taken out of the humid condition, and wiped with moist gauze. The inherent fluorescence of each tooth was adjusted, by holding the tip against a sound smooth surface area (not the experimental one) and pressing the ring button until the calibration was completed for each tooth. One operator with previous experience in the use of Dd device (13) made one laser measurement for each site, by placing the flat tip in contact with dental surface. The peak value that means the maximum value of fluorescence in the tested site was registered for $\mathrm{S}, \mathrm{DE}$, and RE areas of each tooth under humid condition. The laser readings under dry condition were achieved as previously described, after each tooth had been previously air-dried for $10 \mathrm{~s}$ (13).

\section{Statistical Analysis}

To verify the reproducibility of Dd measurements of two devices, one previously calibrated observer measured 102 tooth areas independently and under blind conditions. The readings were done in two different occasions within a 1-week interval. One laser measurement was made for each device under humid condition, and another one under dry condition.

Previous findings in non-cavited caries lesions on free smooth surfaces indicated the cut point $\geq 5$ to represent active white-spot lesions in vivo (13) and in vitro (7). Therefore, in the present study, the laser measurements were distributed considering the following criteria of classification: laser range of $0-4$ was representative of remineralized lesions (RE) and sound enamel (S), and the range of 5-99 was representative of demineralized lesions (DE). 
The classification in the categorical data lead to $\mathrm{RE}+\mathrm{S}$ and DE categories, suggesting the application of kappa statistics $(\kappa)$ in the following situations: intra-rater agreement, in the use of the devices, and inter-device agreement. Kappa statistics was applied by point, and by $95 \%$ of confidence interval $\left(\mathrm{CI}_{95 \%}\right)(16)$. Kappa values were classified according to the standards proposed by Landis and Koch (17).

In order to be considered a useful method, it was assumed by the present study that each laser device should be able to distinguish between different diagnostic meanings in at least $61 \%$ of the times it would be used in caries diagnosis. This would mean a substantial reproducibility (17).

\section{RESULTS}

Table 1 shows the range of the laser values for Dd X and Dd Y, according to the first and second examinations, under humid and dry conditions, on each area under experiment.

Similar laser intervals were observed for the first and second assessments in each area under experiment. When the intervals of device $\mathrm{X}$ were compared to the ones of device Y, slight differences were observed between the values of DE and RE areas. On the other hand, $\mathrm{S}$ areas had exactly the same laser values, with a

Table 1. Minimum and maximum laser values of Dd X and $\mathrm{Y}$, according the first $\left(1^{\text {st }}\right)$ and second $\left(2^{\text {nd }}\right)$ examinations, under humid and dry conditions.

\begin{tabular}{|c|c|c|c|c|}
\hline & & & Dd X & Dd Y \\
\hline \multirow{6}{*}{ Humid } & \multirow{2}{*}{$\mathrm{DE}$} & $1^{\text {st }}$ & $2-6$ & $2-6$ \\
\hline & & $2^{\text {nd }}$ & $2-6$ & $1-5$ \\
\hline & \multirow{2}{*}{$\mathrm{RE}$} & $1^{\text {st }}$ & $2-6$ & $1-6$ \\
\hline & & $2^{\text {nd }}$ & $2-7$ & $1-5$ \\
\hline & \multirow{2}{*}{$\mathrm{S}$} & $1^{\text {st }}$ & $1-3$ & $1-3$ \\
\hline & & $2^{\text {nd }}$ & $1-3$ & $1-3$ \\
\hline \multirow{6}{*}{ Dry } & \multirow{2}{*}{$\mathrm{DE}$} & $1^{\text {st }}$ & $3-13$ & $2-9$ \\
\hline & & $2^{\text {nd }}$ & $3-13$ & $1-8$ \\
\hline & \multirow{2}{*}{$\mathrm{RE}$} & $1^{\text {st }}$ & $4-15$ & $3-9$ \\
\hline & & $2^{\text {nd }}$ & $3-16$ & $3-9$ \\
\hline & \multirow{2}{*}{$\mathrm{S}$} & $1^{\text {st }}$ & $1-3$ & $1-3$ \\
\hline & & $2^{\text {nd }}$ & $1-4$ & $1-4$ \\
\hline
\end{tabular}

slight increase in the second assessment after drying. Although $\mathrm{S}$ areas showed coincident laser values in the bracket 1-3 and 1-4, DE and RE areas showed a higher range of the laser measurements, especially after drying, independently of the device. Device X showed a higher variation of the laser intervals in DE and RE areas, than device $\mathrm{Y}$, after drying.

Table 2 shows the intra-rater agreement of Dd devices under humid and dry conditions in each experimental area.

Device X showed a moderate reproducibility under humid condition, which was lower than the expected level of 0.61 . After drying, reproducibility values raised from moderate to almost perfect agreement. Slightly different results by point were observed for intra-rater reproducibility. Device Y had a substantial agreement under humid and dry conditions. In relation to the confidence intervals, both devices reached kappa values above 0.61 , which can be considered an acceptable intra-rater agreement. Based on such finding, the devices were compared in relation to the classification criteria ( $\mathrm{RE}+\mathrm{S}$ and $\mathrm{DE}$ ) to obtain the inter-device reproducibility. This way Dd X and Y were compared under humid and dry condition, and it was chosen the classification of laser values obtained in the first assessment.

Tables 3 and 4 show the inter-device reproducibility of devices $\mathrm{X}$ and $\mathrm{Y}$, under humid and dry conditions,

Table 2. Intra-rater reproducibility by point $(\kappa)$, by confidence interval $(\mathrm{CI})$, and classification (Class) for Dd X and Y in DE and $\mathrm{RE}+\mathrm{S}$, under humid and dry conditions.

\begin{tabular}{|c|c|c|c|c|}
\hline & & & Dd X & Dd Y \\
\hline \multirow{6}{*}{ Humid } & \multirow{4}{*}{$\mathrm{DE}$} & $\kappa$ & 0.57 & 0.68 \\
\hline & & CI & $0.24-0.90$ & $0.49-0.87$ \\
\hline & & Class & Moderate & Substantial \\
\hline & & $\kappa$ & 0.49 & 0.68 \\
\hline & \multirow[t]{2}{*}{$\mathrm{RE}+\mathrm{S}$} & CI & $0.26-0.73$ & $0.49-0.87$ \\
\hline & & Class & Moderate & Substantial \\
\hline \multirow{6}{*}{ Dry } & \multirow{3}{*}{$\mathrm{DE}$} & $\kappa$ & 1.0 & 0.64 \\
\hline & & CI & $0.67-1.0$ & $0.31-0.97$ \\
\hline & & Class & Almost Perfect & Substantial \\
\hline & \multirow{3}{*}{$\mathrm{RE}+\mathrm{S}$} & $\kappa$ & 1.0 & 0.67 \\
\hline & & CI & $0.77-1.0$ & $0.46-0.88$ \\
\hline & & Class & Almost Perfect & Substantial \\
\hline
\end{tabular}


respectively.

The reproducibility between devices was slight under humid condition $(\kappa=0.17)$, and the confidence interval did not include the expected level of agreement initially proposed $(0.61)$. Under dry condition the reproducibility was substantial $(\kappa=0.62)$, and the confidence interval included the expected level of 0.61 , suggesting that the device was useful.

\section{DISCUSSION}

The present investigation aimed to investigate the reliability of Dd devices to detect caries-like lesions on free smooth surfaces, when the diagnosis was performed with two different devices (denominated $\mathrm{X}$ and $\mathrm{Y}$ ), under humid and dry conditions of the substrate. No previous study was found to evaluate Dd ability to detect caries-like lesions after the same enamel areas had been demineralized by $\mathrm{pH}$-cycling and then remineralized.

The exact mechanism of laser detection has not been fully articulated (18). It appears to measure the fluorescence of bacterial metabolites - porphyrins play a major role - within carious lesions, rather than crystalline disintegration (18). Both inorganic and organic molecules in the tooth substance absorb the light emitted by Dd, and infrared fluorescence occurs (11). Fluorescence increases in the presence of carious tooth substance (11). The emitted fluorescence is then collected through the tip, and passes into ascending fibres in order to finally be processed and displayed as a number ranging from 0 to 99 (11), with zero indicating a minimum fluorescence and 99 a maximum of fluorescent light.

Although the display can register numerical values until 99, the maximum values obtained in the present study for DE and RE areas were 16 for device $\mathrm{X}$, and 9 for device $\mathrm{Y}$ (Table 1) indicating that the full capacity of Dd was not reached under in vitro conditions. Comparing laser values obtained in $\mathrm{S}$ areas

Table 3. Reproducibility between Dd X and Y (humid condition).

\begin{tabular}{ccccc}
\hline & \multicolumn{3}{c}{ Dd Y } \\
\cline { 3 - 5 } & & $\mathrm{RE}+\mathrm{S}(0-4)$ & $\mathrm{DE}(5-16)$ & Total \\
\hline \multirow{2}{*}{$\mathrm{Dd} \mathrm{X}$} & $\mathrm{RE}+\mathrm{S}(0-4)$ & 80 & 2 & 82 \\
& $\mathrm{DE}(5-16)$ & 17 & 3 & 20 \\
\hline \multirow{2}{*}{ Total } & 97 & 5 & 102 \\
\hline
\end{tabular}

$\mathrm{p}_{\mathrm{o}}=0.81 ; \mathrm{p}_{\mathrm{e}}=0.77 ; \kappa=0.17\left(\mathrm{CI}_{95 \%}: 0.04-0.30\right)$ - Slight agreement; $\mathrm{s}=0.07 ; \mathrm{p}<0.05$ with the obtained in DE areas under humid condition, it was noticed an increase of three laser units, what is in agreement with Mendes and Nicolau (4), who investigated artificial caries lesions formed by $\mathrm{pH}$ cycles in primary teeth. However, a higher increase in fluorescence units was observed after drying. Laser values varied from 7 to 9 units for device $X$, and from 3 to 4 units for device $Y$ (Table 1), leading to different classification of lesion activity, respectively.

Comparing S and DE areas (Table 1), the increase in laser readings after teeth were demineralized and the visual appearance of white-spot lesions indicate the effectiveness of the $\mathrm{pH}$-cycling based on Featherstone et al. (13) to produce caries like-lesions. This way Dd was able to detect alterations produced by the artificial caries model in enamel of bovine teeth.

However, similar range of the laser values for $\mathrm{RE}$ and DE areas was observed (Table 1), showing that Dd did not seem to differentiate between demineralized and remineralized lesions in bovine teeth. This is in agreement with the findings of Mendes et al. (6), who remineralized natural incipient caries lesions of primary teeth in vitro, and verified that although mineral gain was obtained, Dd was not considered as an adequate instrument for measuring remineralization in vitro.

Lower laser values were observed in vitro when compared to in vivo results in natural lesions on free smooth surfaces (13), despite the limitation of this comparison. Although it could be a spurious finding, a possible explanation could be related to the pore structure of a caries-like lesion, which is different from the pore structure of a natural incipient lesion (19). Also, the surface layer of natural lesions is thicker and has a higher mineral content than that of lesions developed in vitro (19). Other fact is that Dd readings were observed to increase more steeply when lesions extended into dentin $(4,6)$. This is not the case of chemically demineralized bovine enamel lesions, which are very homogeneous

Table 4. Reproducibility between Dd X and Y (dry condition).

\begin{tabular}{ccccc}
\hline & \multicolumn{3}{c}{ Dd Y } \\
\cline { 3 - 5 } & & $\mathrm{RE}+\mathrm{S}(0-4)$ & $\mathrm{DE}(5-16)$ & Total \\
\hline \multirow{2}{*}{$\mathrm{Dd} \mathrm{X}$} & $\mathrm{RE}+\mathrm{S}(0-4)$ & 37 & - & 37 \\
& DE (5-16) & 20 & 45 & 65 \\
\hline \multirow{2}{*}{ Total } & 57 & 45 & 102 \\
\hline
\end{tabular}

$\mathrm{p}_{\mathrm{o}}=0.80 ; \mathrm{p}_{\mathrm{e}}=0.48 ; \kappa=0.62\left(\mathrm{CI}_{95 \%}: 0.44-0.80\right)-$ Substantial agreement; $\mathrm{s}=0.09 ; \mathrm{z}=6.77 ; \mathrm{p}<0.05$ 
when compared to the biofilm-formed lesions that are developed in vivo. Another explanation could be related to the fact that Dd is a good negative predictor, since low readings ( 10 and below) indicated no caries $64 \%$ of the time (3). Also, it has been indicated that its ability to distinguish between sound tooth structure and caries was optimal when readings were in a range of 15 to 20 (3).

Bovine teeth were chosen because they have a relatively more uniform chemical composition, providing a less variable response to cariogenic challenge than human teeth, which are usually of inconsistent age and source and of a highly variable composition that result in large variation in their response under in vitro acidic challenge (20). Also, bovine teeth have advantages of being easier to obtain and manipulate (20), and they have been used to evaluate caries development and inhibition, under $\mathrm{pH}$ cycling $(14,15,20)$.

Regarding laser fluorescence, drying can change the properties inside a lesion, and produce an increase in the fluorescence path, changing the produced fluorescence values. When enamel is air-dried whether sound or carious, light scattering occurs in air instead of in water (19). There is more scattering and less fluorescence in dry enamel than in wet enamel (19), due to a decrease in the amount of light that hits the fluorescing centers and due to the screening of the fluorescence from dentin or enamel boundary (1).

Different fluorescent values with quantitative light induced fluorescence (QLF) instrument were found (1) due to differences in light scattering in the teeth in wet versus dry samples. In relation to Dd, which is also based in light scattering, there is no recommendation of the need of air drying, but it has been suggested that it would be important to standardize hydration conditions for longitudinal measurements (19).

Based on a previous in vivo study (13), it was decided to dry each surface for $10 \mathrm{~s}$, although wide variation of drying time had been used ( 5 to $20 \mathrm{~s}$ of airdrying with a 3 -way syringe) $(1,12,19)$. In this study, drying promoted an increase in laser fluorescence values of $\mathrm{DE}$ and $\mathrm{RE}$ areas in vitro. This is in agreement with previous results of higher measurements after teeth were air-dried $(1,12)$ or dehydrated (19).

Intra-rater agreement for diagnosing with device $\mathrm{X}$ was improved after $10 \mathrm{~s}$ drying. Intra-rater agreement for device Y remained substantial under both conditions, what means that drying did not affect its performance. When devices $\mathrm{X}$ and $\mathrm{Y}$ were compared, they showed a substantial agreement, under dry condition. As drying did not influence the diagnostic reproducibility of device Y, but improved the diagnostic reproducibility of device $\mathrm{X}$ and also between devices, it is advised to dry the teeth before laser inspection in vitro (Table 2).

The increase in reliability results in dried teeth corroborates the assertion that a filter should ensure that the excitation light would not be interpreted as fluorescence. However, it appears that there is internal fluorescence within the instrument due to this scattered excitation light, which is received by the instrument probe and subsequently measured.

Another important issue is related to the diagnostic meaning of the laser readings. Numerical laser values of Dd devices depend on the severity of the lesions and on which tooth surface the diagnosis is being performed. Minor variations of laser readings could be taken acceptable when measuring the same lesion repeatedly, depending on the range that it occurs. Therefore, instead of comparing numerical values between first and second assessments, the present study distributed the numerical values in categorical data, based on previous scales obtained in free smooth surfaces for natural lesions in vivo (13), and for incipient lesions in vitro (7). As the laser values between 0 and 4 were indicative of arrested lesions and sound enamel under in vivo conditions (13), it was decided to group the laser results for RE and $\mathrm{S}$ areas in the same category when reproducibility results were verified in vitro. Laser values higher than 5 represented $\mathrm{DE}$ areas. This cut point was also observed in primary teeth, in incipient caries lesions formed in vitro in free smooth surfaces (7), in which a Dd value $\geq 5$ indicated carious teeth.

In order to be considered as reliable tools, different Dd devices should produce the same measurements of caries lesion, which means to produce reproducible results in caries diagnosis. Poor inter-device reproducibility by point and by confidence interval was found under humid condition. However, the level of interdevice agreement was substantial under dry condition. Different devices were reliable to detect artificial caries in free smooth surfaces of bovine teeth only under dry condition. Attention should be taken when replacing Dd devices, especially if they are used to monitor caries process in free smooth surfaces under humid condition.

Other studies evaluated the level of agreement between repeated laser measurements by using more than one Dd device in occlusal surfaces in vitro (8-10) and in vivo $(8,9,11)$. However, it was not found in the literature any consideration regarding the use of different devices 
in free smooth surface. Although care should be taken to compare our findings with the available ones, they are in agreement with previous reports (11) that also found minor differences between devices, and are against the recommendation of changing devices, as previously recommended for occlusal surfaces (8-10). Contrary to these reports, changing devices were recommended for caries diagnosis in occlusal surfaces (8-10). Good reproducibility were found in vitro $(0.89-0.97)$ and in vivo (0.88-0.90) (8), indicating an almost perfect reliability. Kunisch et al. (9) verified good inter-examiner reproducibility (0.74-0.98). Another study (10) showed reliable results between devices, and recommended their replacement, provided the same tip would be used.

The present results indicate that under dry conditions, it is possible to replace Dd devices to detect caries-like lesions in free smooth surfaces in vitro. Drying for $10 \mathrm{~s}$ is recommended to assure reliability in the diagnosis of caries lesions. This study was conducted using an in vitro methodology, which could be a limitation regarding caries diagnosis in clinical restorative dentistry. Further studies under in vivo conditions are needed to evaluate the performance of these devices and confirm our findings.

\section{RESUMO}

Este estudo verificou o efeito da secagem sobre o resultado de reprodutibilidade de aparelhos laser DIAGNOdent (Dd) no diagnóstico de cárie artificial. Três áreas foram produzidas em cada um dos 34 incisivos bovinos: hígida (S), desmineralizada (DE) e remineralizada (RE). Um examinador mediu cada área com dois aparelhos Dd (denominados $\mathrm{X}$ e Y), sendo duas vezes sob a condição úmida e duas vezes sob a condição seca. A concordância intra-examinador segundo cada aparelho, e a concordância entre

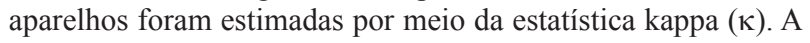
reprodutibilidade intra para o aparelho $\mathrm{Y}$ foi substancial sob a condição úmida ( $\kappa_{\mathrm{DE}}=0,68$ e $\left.\kappa_{\mathrm{RE}+\mathrm{S}}=0,68\right)$ e seca $\left(\kappa_{\mathrm{DE}}=0,64\right.$ e $\kappa$ $\left.\mathrm{RE}_{\mathrm{S}}=0,67\right)$. Para o aparelho $\mathrm{X}$, a concordância foi substancial sob a condição úmida $\left(\kappa_{\mathrm{DE}}=0,57\right.$ e $\left.\kappa_{\mathrm{RE}+\mathrm{S}}=0,49\right)$ e foi quase perfeita após a secagem $\left(\kappa_{\mathrm{DE}}=1,0\right.$ e $\left.\kappa_{\mathrm{RE}+\mathrm{S}}=1,0\right)$. A concordância entre aparelhos foi fraca $(\kappa=0,17)$ na condição úmida, porém foi substancial na condição seca $(\kappa=0,62)$. Como a reprodutibilidade foi melhor sob a condição seca, a secagem da superfície dentária é aconselhada para se detectar lesões de cárie incipientes em superfícies lisas livres, quando mais de um aparelho é utilizado no diagnóstico.

\section{REFERENCES}

1. Mujat C, van der Veen MH, Ruben JL, Dogariu A, ten Bosch JJ. The influence of drying on quantitative laser fluorescence and optical pathlengths in incipient natural caries lesions. Caries Res 2004;38:484-492.

2. De Benedetto MS, Morais CC, Novaes TF, de Almeida Rodrigues
J, Braga MM, Mendes FM. Comparing the reliability of a new fluorescence camera with conventional laser fluorescence devices in detecting caries lesions in occlusal and smooth surfaces of primary teeth. Lasers Med Sci 2010 Feb 16. DOI: 10.1007/s10103-0100757-1. [Epub ahead of print].

3. Tagtekin DA, Ozyoney G, Baseren M, Ando M, Hayran O, Alpar R, et al.. Caries detection with DIAGNOdent and ultrasound. Oral Surg Oral Med Oral Pathol Oral Radiol Endod 2008;106:729-735.

4. Iwami Y, Yamamoto H, Hayashi M, Ebisu S. Relationship between laser fluorescence and bacterial invasion in arrested dentinal carious lesions. Lasers Med Sci 2010 Jun 10. DOI: 10.1007/s10103-0100798-5. [Epub ahead of print].

5. Mendes FM, Nicolau J. Utilization of laser fluorescence to monitor caries lesions development in primary teeth. J Dent Child 2004;71:139-142.

6. Shi XQ, Tranaeus S, Angmar-Månsson B. Comparison of QLF and Dd for quantification of smooth surface caries. Caries Res 2001;35:21-26.

7. Mendes FM, Nicolau J, Duarte DA. Evaluation of the effectiveness of laser fluorescence in monitoring in vitro remineralization of incipient caries lesions in primary teeth. Caries Res 2003;37:442444.

8. Alwas-Danowska HM, Plasschaert AJ, Suliborski S, Verdonschot EH. Reliability and validity issues of laser fluorescence measurements in occlusal caries diagnosis. J Dent 2002;30:129-134.

9. Kühnisch J, Ziehe A, Brandstädt A, Heinrich-Weltzien R. An in vitro study of the reliability of Dd measurements. J Oral Rehabil 2004;31:895-899.

10. Naphausen MT, Riemersma M, Verdonschot EH. Diagnosis of occlusal caries lesions using laser fluorescence measurements. Ned Tijdschr Tandheelkd 2002;109:3-7.

11. Tranaeus S, Lindgren LE, Karlsson L, Angmar-Mansson B. In vivo validity and reliability of IR fluorescence measurements for caries detection and quantification. Swed Dent J 2004;287:173-182.

12. Shi XQ, Welander U, Angmar-Månsson B. Occlusal caries detection with KaVo Dd and radiography: an in vitro comparison. Caries Res 2000;34:151-158.

13. Pinelli C, Campos Serra M, de Castro Monteiro Loffredo L. Validity and reproducibility of a laser fluorescence system for detecting the activity of white-spot lesions on free smooth surfaces in vivo. Caries Res 2002;36:19-24.

14. Featherstone JDB, O'Reilly MM, Shariati M, Brugler S. Enhancement of remineralization in vitro and in vivo. In: Factors Relating to Deminealization and Remineralization of the Teeth. Leach SA (Editor). Oxford: IRL Press, 1986. p.23-34.

15. Serra MC, Cury JA. The in vitro effect of glass-ionomer cement restoration on enamel subjected to a demineralization and remineralization model. Quintessence Int 1992;23:143-147.

16. Light RJ. Measures of response agreement for quantitative data: some generalizations and alternatives. Psychol Bull 1971;76:365377.

17. Landis JR, Koch GG. The measurement of observer agreement for categorical data. Biometrics 1977;33:159-174.

18. Pretty IA, Maupomé G. A closer look at diagnosis in clinical dental practice: part 5. Emerging technologies for caries detection and diagnosis. J Can Dent Assoc 2004;70:540a-540i.

19. Al-Khateeb S, Exterkate RAM, de Josselin de Jong E, AngmarMånsson, Ten Cate JM. Light-induced fluorescence studies on dehydration of incipient enamel lesions. Caries Res 2002;36:25-30.

20. Hara AT, Queiroz CS, Paes-Leme AF, Serra MC, Cury JA. Caries progression and inhibition in human and bovine root dentine in situ. Caries Res 2003;37:339-344. 